Post Walrasian Macro Policy and the Economics of Muddling Through

by

D avid Colander

August 2003

MID D LEBURY COLLEGE ECONO MICS D ISCUSSION PAPER NO. 03-22

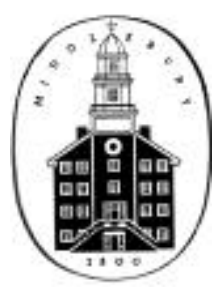

DEPARTMENT OF ECONOMICS

MIDDLEBURY COLLEGE

MIDDLEBURY, VERMONT 05753

http:/ / www.middlebury.edu/ econ 


\section{Post Walrasian Macro Policy and the Economics of Muddling Through}

Post Walrasian economics is the future of economics, or at least I'd like to think so. Actually, I started using the term a while ago, and hoped that it would catch on, but it didn't to any great extent. So when Mark called and offered me the chance to discuss Post Walrasian macro policy, I jumped at it, because it showed that at least someone knew of the term, and there was a chance that it might catch on.

What I though I'd do in this talk is to expand on my earlier discussion of Post Walrasian economics (Colander 1994), and relate it to policy, expanding upon an article I did with Hans van Ess. (Colander and van Ess, 1994) I divide the talk into three parts. First, I define what I mean by Post Walrasian macroeconomics. Second, I discuss some of the theoretical differences between Post Walrasian and Walrasian macro theorizing as they relate to policy. Finally, I discuss how an acceptance of Post Walrasian economics might change the focus of macro policy discussions.

\section{Definition and Terminology}

I'm a historian of recent economic thought, which means I try to make what's happening in the profession understandable to people outside the profession. That's not an easy task, since, often, even those of us inside the profession don't know what is happening. Classifications are important to historians of thought because they provide the framework through which we tell the story of the development of economics to students.

Back in the 1960s, when I learned macroeconomics, it was presented by historians of recent economic thought as a debate between fairly well specified and distinguishable schools of macro economists--Keynesians, neoclassicals, monetarists, and radicals. Those distinctions broke down in the 70 s and 80 s as the issues that had seemed to separate those groups evolved into other issues, or were simply dropped unresolved, as the profession moved on to new debates. This evolution led to a variety of new classifications - new classical, neoKeynesian, new Keynesian, Post Keynesian, (with various hyphens and capitalizations)--and by the 1980s the classification situation could best be described as classification anarchy. By the 1990s, the debates in macro had further evolved, and even those new terms no longer were useful in capturing the differences among various economists on macro policy. The pedagogical reaction to that anarchy was to downplay differences among schools in the texts, and to present macroeconomics as a unified approach. ${ }^{1}$ In the texts there were no longer Keynesians, monetarists, or Classicals; there were simply macroeconomists.

The tendency to downplay differences among macroeconomists was amplified because at the same time the debates in macro were evolving, the profession itself was evolving, causing the term "neoclassical" to lose much of its relevance as a descriptor of modern economics. (See Colander 200 ) The economics that has emerged in the $21^{\text {st }}$ century is significantly different than

\footnotetext{
${ }^{1}$ Textbooks lag the profession by a decade at least, and while the intermediate texts present a unified approach, it is not presented in a fashion consistent with modern theoretical macroeconomists, but rather within an IS/LM framework based on demand and supply for money and savings investment equilibria rather than intertemporal equilibrium. More recent work, such as that found in the Handbook of Macroeconomics (Woodford and Taylor 199 ) provides a dynamic stochastic intertemporal equilibrium foundation for the new integration (McCallum and Nelson, 1999) and will likely be working its way into the intermediate texts in the next few years. (See Colander 2004.)
} 
the economics described as neoclassical in the history of thought texts. Modern economics has loosened its connection to the holy trilogy-rationality, equilibrium, and greed--and moved toward a much broader trilogy, which might be described as cognitive awareness, purposeful behavior, and sustainability. This broader trilogy allows a much broader range of models than did the old trilogy, and the acceptance of this new trilogy eventually will change the way economics is done. ${ }^{2}$

The degree to which the trilogy is violated varies among economists, but what I mean by this evolution is that top graduate schools no longer automatically shun individuals who do not maintain a belief in the old trilogy. Thus, we see work in behavioral economics, non-linear dynamics, evolutionary game theory, statistical pattern analysis (econophysics), and experimental economics as acceptable elements of conventional economics. Examples abound; Peter Howitt is at Brown; Buz Brock is as Wisconsin; Mat Rabin is at Berkley, David Laibson is at Harvard; Xavier Gabaix is at MIT; the list could be significantly expanded.

The change is ongoing, but undergraduate students have little sense of the change since it has not yet shown up, other than in the ubiquitous boxes that students don't read, in standard undergraduate texts. In my view, however, good conventional economists are open to issues framed in this broader trilogy, and cutting edge work in economics is usually tied in some way to these changes. (Of course, I define good as an economist who is open to at least thinking about these issues.)

As I struggled with the problems of relating the debates in macroeconomic policy to students that I felt still existed, I found myself developing finer and finer characteristics - for example comparing the new new Keynesian economics with the new neoKeynesian economics. As I reflected upon these distinctions I came to the conclusion that the Keynesian-based comparisons at this point were beyond the grasp of any non-specialist, and thus not especially helpful as classifiers. (Colander) This led me to give up on the old classifications and move to a new Walrasian/Post Walrasian classification that was not burdened by the historical baggage of the earlier classifications.

Others, such as Sam Bowles and Herb Gintis ( ) and Joe Stiglitz ( ) did the same, (although we used it somewhat differently) and the term, Post Walrasian, became part of the vocabulary of those economists who have a proclivity toward classifications. However, while it is part of the vocabulary, it has hardly caught on; I would say it is emerging, but not yet emergent, which means that its use has not gone beyond the occasional mention in the journals. But I am hopeful that it will catch on, because I see it as a useful term to help students and outsiders understand recent developments and in the debates in macro and macro policy.

Now that I've given the context, let me now turn to what I mean by Post Walrasian economics. In Colander (1996) I specified three characteristics of Post Walrasian economics. Those three characteristics were:

1. Multiple equilibria and complexity

\footnotetext{
${ }^{2}$ With that evolution, not only did the term neoclassical lose its relevance, so too did the term, heterodox, since heterodox had generally been defined in opposition to a neoclassical orthodoxy. As the orthodoxy evolved and broadened, what heterodox economists were in opposition to became hazier, and in the 2000s it is no longer possible to easily distinguish orthodox from heterodox economics in terms of content. These ideas are expanded upon in Colander, Holt and Rosser. (forthcoming)
} 


\section{Bounded rationality}

3. Institutions and non-price coordinating mechanisms

These are all aspects of the movement away from the holy trilogy and toward the broader and looser foundational requirements of theorizing. None of these are characteristics of Post Walrasian economics alone, and, in fact, most are aspects that heterodox economists have been pushing for years. What's changed in the past decade is that mainstream economics is beginning to embrace them and include research based on them as part of the conventional research program. The Post Walrasian classification encompasses both mainstream and nonmainstream economists.

What hasn't followed from conventional economics is a significant discussion of the policy implications of this expanded research program. Instead, in an effort to tie policy to theory, the conventional discussion of policy almost inevitably remains in reference to a Walrasian model. ${ }^{3}$ Thus, much of the Post Walrasian policy discussion has primarily been within the heterodox community, because they have been willing to follow up the policy implications of the broader holy trilogy.

I suspect that the reason why conventional economics has tied its policy approach to the Walrasian model is that once one moves to the broader trilogy, a model can be devised to support a wide range of policy, and theory becomes far less useful. Put bluntly, in terms of drawing out policy conclusions from the theory, giving up the holy trilogy means that almost anything goes, and that formal theory can no longer be used as a direct guide for policy. When you have models with multiple equilibria, path dependency, non-linear dynamics, endogenous tastes, institutional restrictions, and historesis, there are so many degrees of freedom that theory presents little in the way of restrictions on policy. With that many degrees of freedom a sufficiently capable modeler can devise a theoretical model to support any policy. What this means is that if one accepts the broader trilogy, theory must acquire a different purpose; its use must change from theory guiding policy to theory and models aiding one's intuition.

\section{Theoretical Differences and Policy}

To see the policy differences between the Walrasian and Post Walrasian approaches it is helpful to consider their underlying visions. Walrasian economics has, as its underlying vision, the standard Walrasian general equilibrium model of the economy. It focuses on a unique equilibrium model where market failures are characterized as deviations from optimality. Its research strategy is to develop that model from its microfoundations, and analyze what a rational individual would do if he or she had full information about the economy. Put another way, Walrasian economics is the study of how infinitely rational individuals operate in a rich information environment.

Post Walrasian economics has a different underlying vision. It sees the economy as too complicated to have a meaningful microfoundations. It sees individuals as bright, but not bright enough to exhibit full rationality. Full intertemporal rationality is impossible to even contemplate

\footnotetext{
${ }^{3}$ This is true in both micro and macro; in this paper I concentrate on macro policy issues.

${ }^{4}$ Once in a while a conventional economist explores policy outside the standard model. An example is Joe Stiglitz's ( ) recent work. 
since agents are seen as changing and evolving. For example, the agent as a child is only tangentially related to the same agent as a retiree; the experiences of growing up shape the rationality of the adult. ${ }^{5}$

On the macro level the result of agent interaction in such a complex environment should be chaos, but that chaos is prevented by the development of institutions and codes of ethics that limit agent's actions. Thus, rather than destabilizing the economy, preventing the achievement of full equilibrium, as is the case in the Walrasian vision, institutions and bounded rationality become ways in which the economy is stabilized. The central question for Post Walrasians is not: Why does the economy exhibit instability and fluctuations?; it is: Why does it exhibit as little instability as it does? The Post Walrasian answer is that bounded rationality and institutions limit individual's actions to a subset that maintain aggregate stability. In such a complex environment institutions naturally become a central element in the study of the economy and the rationality assumptions used in any model are institution-specific. Thus, in contrast to Walrasian economics, post Walrasian economics is the study of how reasonably bright individuals operate in an information poor environment. ${ }^{6}$

\section{From Control to Muddling}

In relating theory to policy, this change in focus requires a change in the way welfare economics and applied policy is thought about. Conventional welfare economics follows what might be called an economics of control approach. It assumes that policy makers know the underlying generating functions of the economy, and that the policy goal is to optimize a social welfare function subject to constraints. Not only are agents assumed to be infinitely bright and operating in rich information sets, but so to are policy makers. Conventional welfare economics is the analysis of how infinitely bright policy makers operate within rich information sets.

The Keynesian economics I learned (which is more appropriately called neoKeynesian) also used an economics of control approach, following a functional finance view in which macro policy makers operated in an information rich environment. Abba Lerner presented both micro and macro approaches in his Economics of Control, which played a key role in establishing the textbook foundations for economic policy analysis. The basis for policy in the two branches of economics was not parallel. In micro, both agents and policy makers were assumed to operate in rich information environments and to have infinite computing capabilities. However, in macro that was not the case. Macro welfare analysis--functional finance--differed from micro welfare analysis because it assumed that agents operated in an information poor environment and had limited computing capabilities, but that policy makers operated in a rich information environment and had infinity computing capabilities.

As the microeconomic foundations of macroeconomics were explored, and the two approaches integrated, the neoKeynesian policy analysis, which was based on Lerner's functional finance welfare approach, was attacked by New Classical economists on consistency grounds. New Classical economists argued that if policy makers had full information, rational

\footnotetext{
${ }^{5}$ In such an environment policy not only affects agents actions; it also affects agent's underlying utility function, so a social welfare specification of optimal policy based on agent's utility functions is impossible unless one works with agent's policy invariant utility functions. Work in the foundations of behavioral economics and meta-utility analysis is beginning to explore this issue.

${ }^{6}$ I see the early Keynesian economics as a movement toward this Post Walrasian vision, although it was quickly derailed into a Walrasian framework.
} 
individuals should also be assumed to have full information available to them. And if agents have that information, then much of the benefits of Keynesian policies are eliminated; in fact, most of the Keynesian problems of stabilization and equilibrium at undesirable unemployment levels would not exist. ${ }^{7}$ Fluctuations are simply reflections of shifts in intertemporal choices, or irreducible noise in the stochastic system, and unemployment is simply the result of intertemporal inconsistencies combined with institutional rigidities. This lack of consistency between agent and policy maker assumptions played an important role in the movement away from Keynesian economics and the development of the modern dynamic stochastic intertemporal equilibrium approach to macro. ${ }^{8}$

Model consistency between agent's information sets and policy maker's information sets seems logically desirable; if policy makers have access to that information, then why shouldn't the agents in the model also have access to it, at least at a cost? So modern Walrasian macro is defensible on these consistency grounds. The Post Walrasian argument is that there is another way to achieve the consistency; rather than assume both individuals and policy makers have full rationality and rich information sets, as conventional Walrasian macro does, the Post Walrasian approach is to start from the other direction-- to assume both policy makers and agents are operating within an information poor environment, and, while bright, are not infinitely bright. In the Post Walrasian vision no agreed upon model of the economy is available. Not only are agents muddling, using rules of thumb, and lacking in a firm foundation in what they are doing, so too are economic policy makers and economists. In muddling through economic policy becomes far less grand; it becomes the search for rules of thumb that work temporarily in a specific institutional environment. As institutions evolve, these rules of thumb also evolve. Muddling through is a pragmatic exploration of policy that is used when one does not have the correct model, or when one does not know a method of determining the correct model.

This difference in view has significant implications for how we think of economists' role in policy, and in how we relate theory to policy. In post Walrasian economics there is no hope for finding an optimal policy; instead all we try to do is to help policy makers make slightly better choices than they otherwise would have.

I see Post Walrasian policy work operating on two fronts. One of these fronts is what might be called a research and development front; it explores alternative institutional environments that might improve the operation of the economy. An example of theoretical research that serves as a foundation for such applied policy might be Mundell's optimal currency work that explored the nature of currency systems that were not tied to nation's borders. Another is Abba Lerner's and my work on market based incomes policies that explored the nature of price controls and the aggregate constraint that unit of account stability places on the steady state equilibrium of a system. Such speculative work is about the implications of different institutional

\footnotetext{
${ }^{7}$ An example of the implications of this approach for policy can be seen in Robert Lucas's recent Presidential address (AER 2003) in which he argued that stabilization has little welfare gain, and that the policy focus of macro should be on growth.

${ }^{8}$ The reason for the downfall of Keynesian economics is debatable, and my argument does not depend on it. Post Keynesians question whether Keynesian economics truly made that assumption, and argue that it is neoKeynesian economics, not the true Keynesian economics, that has fallen. Paul Davidson's focus of Keynesian economics on the nonergodicity of the system is consistent with the argument I am making. As I discuss in Colander (forthcoming) the functional finance approach to macro policy remained in policy makers and in the undergraduate texts because of the lags involved, and because they had to deal with real world policy issues.
} 
arrangements. It is broad and suggestive and is designed to get people thinking about issues in a different way than they previously have.

The second front of Post Walrasian policy is much more specific; it accepts the existing institutions and considers how those existing institutional arrangements might be improved. Whereas the research and development work is broad and general, this work is specialized and often technical. The researcher begins from specific problems and then chooses a model incorporating general insights that seem to fit. The problems define the research topic, not the model and data availability as is generally currently the case. ${ }^{9}$

Much economic policy work in microeconomics follows what I am calling this Post Walrasian methodology. It is little tied to abstract Walrasian theory, is not dependent on hyper rationality, and is institution specific. It was central to Milton Friedman's approach (see Hirsch and diMarchi) and is the approach that "reduced form" labor economist currently use. These reduced form economists have a loose general theoretical conception of theory, but most of their work is statistical in nature and does not depend on formal general equilibrium theory. It is pragmatic and ad hoc: Do charter schools improve educational outcomes? Does the minimum wage increase unemployment significantly?

"Structuralist" labor economists have attacked that reduced form approach as incorrect, since it has no formal welfare foundation, but in the Post Walrasian view, that attack is meaningless since there exists no formal welfare foundation for policy. The relevance of Post Walrasian applied policy work depends not upon formal welfare analysis, but upon the strength of the arguments it makes - what McCloskey calls its rhetoric, but which might better be called heuristic argumentation based on educated common sense, and technical knowledge.

Early Keynesian and monetarist applied policy both used this reduced form applied policy approach, but then in debates, Keynesians started structuring their models in a Walrasian framework and adding a general equilibrium foundation to their analysis where individuals were assumed to have infinite computing powers. Tobin's work in expanding the asset-analysis in the Keynesian model is an example. As that happened, Keynesian economics evolved into neoKeynesian analysis. In their policy analysis these Keynesian economists kept the functional finance welfare foundations. New Classicals attacked that work as lacking a full micro foundation, and that reduced form Keynesianism has faded in importance. Today, most conventional economists use a stochastic intertemporal equilibrium approach. ${ }^{10}$ This new Classical and New Keynesian work has made Walrasian macro theory an extension of micro theory. In today's conventional applied macro, specific policy proposals are pulled from highly abstract models that assume individual optimization in a full information environment. An example is Chari and Kehoe's analysis of a primal approach to fiscal policy focusing on optimal

\footnotetext{
${ }^{9}$ I recently interviewed Harvard students and asked the difference between sociology and economics. They said that in sociology the important problems define the research agenda, whereas in economics the available models and data sources define the research agenda. Post Walrasian economics expands the number of basic models and increases the range of acceptable data, and follows an approach closer to the sociological approach, but at a more technical level.

${ }^{10}$ Examples of the reduced form approach include Ray Fair's work ( ) and John and Wendy Cornwall's work ( ). So, in part, the post Walrasian approach is simply a return to the earlier macro approach, which proceeds to policy proposals from loosely formulated theories and statistical analysis without the burden of having a firm noncontextual formal microfoundation for theory — in muddling through one cannot have a firm foundation for theory.
} 
taxation (Chari and Kehoe (1999). In it they try to shed light on how monetary and fiscal policy should be set over the long run and over the business cycle. They do so by integrating optimal taxation literature into a Walrasian general equilibrium model. They arrive at four policies (pg. 1673 ) including the need to have capital taxes going to zero after the first period and the interest rate going to zero.

That is not the type of policy work that is seen as useful in the Post Walrasian vision. In Post Walrasian theory models are not representations of realities, but aids in thinking about real problems. The policy implication from one model will not be sufficient to draw any real world policy conclusions; instead, it will be tied with historical understanding and results from other models, and by a heuristic approach that provides one with an initial view of what the problem is and whether the analytic models are providing useful insights. Tom Schelling has called this approach "vicarious problem solving" in which agents are assumed to "operate in a purposeful manner, aware of their values and alert to their opportunities." Using this approach the researcher figures out what an agent might do by imagining him or herself in the person's position, as best he understands that position, and decides what that person will likely do given that person's aims, values objectives, and constraints. (Schelling 2003) This vicarious problem solving approach places limits on the formal analytic models we use. It tells us whether the model's results make sense.

Assumptions of formal models are chosen to match the best representation of the existing reality that one can vicariously get, and the results of formal model are matched or calibrated to the real world data. That is where the new work in developing the new foundational assumptions of economics comes in. In developing ones theory, one uses information gathered from experiments, insights of behavioral economists, and even surveys, such as that of Truman Bewley's work on wage rigidities. When analytic theory fails, one turns to whatever sources of guidance work.

\section{Applying Unfinished Theory to Policy}

The distinction between Walrasian and post Walrasian economics can be overdone. Modern Walrasian economics has gone beyond the standard approach, and there are few economists left who are still limiting their research to the strict Walrasian program. Thus, the relevant contrast for Post Walrasian is with what might be called the extended Walrasian program. This extended Walrasian program loosens the strict Walrasian assumptions in a number of ways. For example, it loosens the information and rationality requirements, and includes an analysis of bounded rationality. Thomas Sargent's work ( ) can be seen along these lines. It also no longer accepts the need for a unique equilibrium, and thus includes multiple equilibria, which in turn make the specification of rationality more complicated, and necessitates a meta-analysis involving equilibria selection mechanisms.

The extended Walrasian program also allows conventions and institutions to be embedded in multiple stages in the optimization process that lead to temporary rules, or limits on agent's behavior in the form of institutions; the macro branch of the new institutional economics and evolutionary game theory could fit within this extended Walrasian program. Optimization still occurs but it's a multiple optimization process that is done in reference to multiple variables changing at different speeds. These emerging, extended Walrasian, research programs are far from their Walrasian origins, and, in my view, eventually the Post Walrasian/Walrasian distinction will itself become untenable as the two approaches converge. But that is years off. 
Where the Post Walrasian approach differs from the Walrasian approach is in how to apply theory to policy in the interim. The Walrasian approach to developing the model is to modify one assumption at a time. The difficulty for policy analysis with this "remove one assumption at a time" approach is that the assumptions are interdependent. If assumptions are interdependent policy results of models that have modified the assumptions are suspect, and when applying models to policy a conservative approach is generally taken, and policy discussion is tied to developed formal Walrasian model, not to the extended Walrasian model. Most conventional macro policy work and discussion, such as inflation targeting, monetary independence, and optimal fiscal policy, growth policy, has followed a conservative connection between theory and policy; connecting policy to the Walrasian models we know and not to the new untested extended Walrasian models that have not yet been significantly explored.

The Post Walrasian approach agrees that the results of models in which assumptions are adjusted one assumption at a time are suspect and not especially useful for policy guidance. But, in most cases, neither is the full information, full rationality model. In Post Walrasian theory one is attempting to develop models in which assumptions are adjusted equally on the margin so that the nature of interrelationships in maintained. This is, of course, not easy to do, since each of the deviations from the core assumptions make the modeling more complicated, and the additional of all of them - institutions, bounded rationality, and multiple equilibria--makes the analytic modeling process from micro foundations integrating all of them impossible.

It is this conservative approach to relating theory and policy that in my view today differentiates heterodox and conventional economists. The conventional approach to base policy on developed theory has given macro policy a highly conservative cast, and has prevented conventional economists from exploring a variety of policy issues. It has been left to nonmainstream economists and the occasional conventional economist, such as Joe Stiglitz, to push the policy envelope. Thus, I would argue that much of this nonconventional work on policy fits nicely under the Post Walrasian heading, and it is in policy where heterodox economists play the most important role.

Rather than starting with a general formal vision of the model, Post Walrasian policy analysis starts with a specific policy problem; and attempts to model an economy where the assumptions match the observed characteristics in the economy. Instead of having a single wellspecified formal model, it has a variety of well-specified formal models, as well as a variety of informal modeling techniques. It uses a combination of these to add insight into policy problems. Eventually this approach will be systematized, and in a book I am currently working on with Buz Brock, we are attempting to do so in what we call the economics of muddling through.

In our approach the first step in any policy analysis is to place it into a category of models. Is it a Walrasian general equilibrium type problem, in which case computable general equilibrium models may provide some insight? Is it a non-linear type problem, in which case statistical mechanics models may be helpful? Is heterogeneity likely to be important, in which case agent-based models may be necessary to provide some guidance as to how the events will transpire? Is the problem likely one of multiple equilibria, where the equilibrium selection mechanism will likely become the focal point of the analysis? Is the problem too complicated for formal analytic specification? Then straight data analysis-such as vector auto regression and cointegration may provide useful insights? As I see it the Post Walrasian economists will come to a problem with a set of statistical and analytical tools to solve problems that policy makers have. How does one tell which approach works? Through a study of the data and history of the 
problem. In the muddling through approach economists are closer to engineers, studying particular problems using a variety of models, than they are to scientists.

I sometimes like to picture the difference in the Walrasian and Post Walrasian approaches to theory and policy in reference to the building of medieval cathedrals. These cathedrals were built following a Post Walrasian approach. The did not rely on scientific laws to guide the building, but instead on accumulated rules of thumb of what worked and what didn't. The building proceeded by trial and error. Different methods of construction would be pushed to the limit until a cathedral caved in somewhere, and then the rules of thumb would change. As the stored knowledge increased, the cathedrals became more grandiose, even without a specific understanding of the laws underlying them. That came much later. Post Walrasian policy follows that same approach. It is conducting policy without a full knowledge of the general laws of the economy, if there are any. What you can find, at best, are general rules of thumb for how things have worked in the past, and possible some exploitable patterns. Walrasian economics follows a different approach to policy; it is a search for the underlying architectural plans of the economy.

\section{A Change in Goals}

Another significant change that I believe occurs when one takes a muddling through approach to policy rather than an economics of control approach involves the goals of policy. For a variety of reasons Walrasian economic policy has focused on efficiency - interpreted as maximum output regardless of distribution of that output - as the goal of policy. ${ }^{11}$ This is in part due to the acceptance of a unique equilibrium and stability of the system, and in part due to the evolution of policy analysis, where economists attempted to remain value free in their analysis. ${ }^{12}$

Because Post Walrasian work relies less on analytic models, and more on simulations, reduced form, heuristic, and agent-based models, which can better handle disaggregation and heterogeneous agents, it can better consider issues of distribution, and thus equity and the total output/distribution tradeoff will become a more important element in policy analysis than it currently is.

The need to include equity in policy analysis has often been remarked upon. But other societal goals are also likely to get more focus. System resilience is one of these goals. In multiple equilibria models, questions of shifts from one equilibrium to another become central to the analysis, and the stability of that equilibrium becomes a policy issue. An important policy question that economics currently does not shed much light on is: Will the institutional structure be sufficiently resilient to withstand the shocks that hit it? If it is not, the economy might well

\footnotetext{
${ }^{11}$ The addition of other goals of policy highlights a terminological shortcut that economists have made when discussing policy. That shortcut is talking about efficiency as a goal of policy. Efficiency, in an of itself, cannot be a goal of society. Efficiency is achieving some outside determined goal as cheaply as possible. Economists have taken to using efficiency as a short hand to referring to the goal of achieving the highest level of market output. This works as a short hand if redistribution is free, or not of concern, and the activities have no influence on other measured, and that the demands are homothetic so that redistribution would not change the measure of aggregate output. But as soon as other goals are included, the term efficiency most appropriately is used as a method incorporating all goals. Thus, what is usually called efficiency should be called maximizing total output.

${ }^{12}$ This argument is developed in the historical chapter of a book I am working on with Buz Brock, The Economics of Muddling Through.
} 
shift to a completely new equilibrium as the institutional structure changes. ${ }^{13}$ Specifically, if one can rank equilibria, the resilience of the system to shocks becomes an important policy issue. Increasing the resiliency of the economy at a good equilibrium becomes an important policy goal to complement distribution and total output goals.

There is a strong case to be made for a negative tradeoff between resiliency and maximizing total output, because maximizing total output often involves using a single "most efficient" method of production. But using a single method of production tends not to be resilient, and if some problem develops with that method, it can cause a sudden shift to another equilibrium. A policy may be efficient, in the sense of achieving maximum output, but that equilibrium may not be resilient, and one may well decide that a less efficient output with more resiliency is better.

A third change in goals that Post Walrasian economics will likely include involves determining policy invariant normative goals of society. thereby integrating normative goals directly into the policy analysis. As behavioral economics deals with meta utility functions and individual irrationalities, these can be built into policy. As the new agent based models give us insight into such issues, we can expect policy goals integrated into the models to become more complicated.

\section{Conclusion}

Let me conclude with some general observations about some changes in thinking about specific macro policy that I believe will occur with an adoption of a Post Walrasian approach. One is that aggregate demand will be given another look as a determinant of growth, since in path dependent and multiple equilibrium models it can significantly change the equilibrium. Growth analysis will not solely focus on supply side issues; aggregate demand and supply will be interrelated, and will be analyzed as interdependent. (Setterfield (.), Colander ( ). In monetary policy, I would see more of a focus on incomes policies as a way of lowering steady state unemployment. These policies have a potential role in models where aggregate equilibrium does not necessarily require micro equilibrium and the price adjustment process exhibits asymmetries.

The argument for these policies will be dependent on models and data analysis, but those models will not tell us whether the policies are good ones or should be implemented; they will simply provide food for thought and reflection - an input into the broader social decision process, not the decision process itself. The motto of neoclassical economics was there's no such thing as a free lunch. The economics of control changed that to one in which free dinners were available to economic controllers through the science of economics. The motto of muddling through goes back to there's no such thing as a free lunch, but adds the proviso that once in a while you can snitch a sandwhich, and policy analysis is designed to snitch a few.

\footnotetext{
${ }^{13}$ In Colander ( ) I argued that deflation--downward price level flexibility--would have such effects and cannot be considered an acceptable adjustment mechanism. This, I believe, was the early Keynesian view of price level flexibility, and much of their applied policy analysis considered maintenance of the system.
} 
Post Walrasian Macro Policy

\section{Bibliography}

Colander

Colander 2004

Colander and van Ess

Lerner, Abba. Economic of control

Lucas, AER

McCallum and Nelson

Sargant

Schelling 2003

Setterfield

Woodford and Taylor 